\title{
Alternating Copolymerization of Cyclopentene, Cyclohexene or Cyclopentadiene with Acrylonitrile
}

\author{
Junji FuruKaWA, Eiichi KobaYASHI, and Tadahiro WAKUI* \\ Department of Industrial Chemistry, Science University of Tokyo, \\ Noda, Chiba 278, Japan \\ *Research Laboratory, Maruzen Oil, Co., \\ Satte, Saitama 340-01, Japan
}

(Received January 19, 1983)

\begin{abstract}
The copolymerization of cyclopentene, cyclohexene or cyclopentadiene with acrylonitrile was investigated in the presence of ethylaluminum chloride as a complexing agent and a transition metal compound as a promotor. In the case of copolymerization of cyclopentene with acrylonitrile, an alternating copolymer was obtained in the presence of an equimolar amount of EtAlCl${ }_{2}$ contained in acrylonitrile. The addition of a transition metal compound enhanced the yield of the copolymer, but brought about no effect on the copolymer composition. A trace amount of $\mathrm{Cr}(\mathrm{acac})_{3}$ was the most effective promotor. Cyclohexene afforded an alternating copolymer in low yield in a nonpolar solvent such as heptane. On the other hand, cyclopentadiene hardly gave any alternating copolymer, but primarily a Diels-Alder adduct. It is noteworthy that cyclopentene or cyclohexene reacts with toluene as the solvent to produce alkylation products of a Friedel-Crafts type. The present monomer systems may prefer ionic species susceptible to side reactions rather than alternating copolymerization.

KEY WORDS Alternating Copolymerization / Friedel-Crafts Reaction /

Ethylaluminum Chloride / Transition Metal Compound / Acrylonitrile /

Cyclopentene / Cyclohexene / Cyclopentadiene / Tricyclopentyltoluene /

Tricyclohexyltoluene /
\end{abstract}

Cycloolefins are known to be capable of polymerizing with ethylene. For example, Natta has discussed the anionic coordination polymerizability of cycloolefins such as cyclopentene or cyclohexene with ethylene in relation to steric factors. ${ }^{1}$ According to one patent, ${ }^{2}$ the copolymer of cyclopentene and acrylonitrile prepared in the presence of ethylaluminum sesquichloride has an alternating structure. In regard to cyclopentadiene, Yamaguchi $^{3}$ reported an alternating copolymerization with $\mathrm{SO}_{2}$ occurring at the 1,4-positions.

This report deals with alternating copolymerization, the catalytic activity of transition metal compounds, and certain simultaneous reactions other than the polymerization.

\section{EXPERIMENTAL}

\section{Materials}

Cyclopentene (CP), cyclohexene $(\mathrm{CH})$, cyclopentadiene (CPD), and acrylonitrile (AN) were purified by distillation over calcium hydride before use. Ethylaluminum dichloride $\left(\mathrm{EtAlCl}_{2}\right)$, diethylaluminum chloride $\left(\mathrm{Et}_{2} \mathrm{AlCl}\right)$, and triethylaluminum $\left(\mathrm{Et}_{3} \mathrm{Al}\right)$ were used after vacuum distillation. Toluene, tetrachloroethane (ICE), and hexane were purified in the usual manner. Transition metal compounds of chemically pure grade were used without further purification. The transition metal compounds may possibly contain trace amounts of water.

\section{Copolymerization}

Copolymerization was carried out in a sealed 
glass tube under a nitrogen atmosphere. Reagents including a transition metal compound, solvent, $\mathrm{AN}$ and an aluminum compound were introduced at $-78^{\circ} \mathrm{C}$ in this order. After shaking the mixture at $-78^{\circ} \mathrm{C}$, cycloolefin or cyclodiolefin was added at $-78^{\circ} \mathrm{C}$. In many cases, the copolymerization proceeded heterogeneously, owing to the low solubility of transition metal compounds. After copolymerization, the reaction mixture was poured into methanol containing hydrochloric acid. The polymer precipitated was filtered and washed with methanol. The residual methanol solution was subjected to the analysis for side reactions. The copolymer yield was calculated on the basis of the total monomer in the feed.

\section{Friedel-Crafts Reaction}

Alkylation products of $\mathrm{CH}$ with toluene were isolated as follows. The residual methanol solution was evaporated. The residue was dissolved in ether, washed three times with water, and then dried. The oily matter obtained was fractionally distilled into two parts and the residue:

mixed cyclohexyltoluenes: bp $120-125^{\circ} \mathrm{C}(20$ $\mathrm{mmHg}), n_{\mathrm{D}}^{20} 1.5250\left(\right.$ bp $92-93^{\circ} \mathrm{C}(2 \mathrm{mmHg})$, $\left.n_{\mathrm{D}}^{20} 1.5256\right),{ }^{4} \mathrm{~m} / \mathrm{e} 174\left(\mathrm{M}^{+}\right), 131,83$.

mixed dicyclohexyltoluenes: bp $160-165^{\circ} \mathrm{C}(4$ $\mathrm{mmHg}), n_{\mathrm{D}}^{20} 1.5368\left(\mathrm{bp} 154-158^{\circ} \mathrm{C}(1 \mathrm{mmHg})\right.$, $\left.n_{\mathrm{D}}^{20} 1.5366\right),{ }^{4} \mathrm{~m} / \mathrm{e} 256\left(\mathrm{M}^{+}\right), 226,187,173,131$, 83 (Found: C, $89.28 \%$; H, 10.72\%. Calcd: C, $89.06 \% ; \mathrm{H}, 10.94 \%$ ).

The distillation residue was column chromatographed on a silica-gel with hexane- $\mathrm{CCl}_{4}(1: 1)$. The first fraction was recrystallized from ethermethanol $(10: 1)$ to give 2,4,5-tricyclohexyltoluene (C-1). The second fraction in the chromatography afforded isomers of tricyclohexyltoluene (C-2).

$\mathrm{C}-1 \mathrm{mp} 137-138^{\circ} \mathrm{C}\left(\mathrm{mp} 135-136^{\circ} \mathrm{C}\right),{ }^{5} \mathrm{~m} / \mathrm{e} 338$ $\left(\mathrm{M}^{+}\right), 295,269,255,226,187,171,131,83$ (Found: C, $88.77 \%$; H, $11.23 \%$. Calcd: C, $88.76 \%$; H, $11.24 \%$ ).

$\mathrm{C}-2 \mathrm{mp} 128-132^{\circ} \mathrm{C}, \mathrm{m} / \mathrm{e} 338\left(\mathrm{M}^{+}\right), 269,255$, 187, 173, 131, 83 (Found: C, 88.63\%; H, $11.37 \%$. Calcd: C, $88.76 \%$; H, $11.24 \%$ ).

Similarly, in the copolymerization of CP with $\mathrm{AN}$, alkylation products were isolated by working up the residual methanol solution as described above.

mixed cyclopentyltoluenes bp $117-122^{\circ} \mathrm{C}(18$ $\mathrm{mmHg}), n_{\mathrm{D}}^{20} 1.5256\left(\right.$ bp $237.5^{\circ} \mathrm{C}(757 \mathrm{mmHg})$,
$\left.n_{\mathrm{D}}^{20} 1.5287\right),{ }^{6} \mathrm{~m} / \mathrm{e} 160\left(\mathrm{M}^{+}\right), 117,69$.

mixed dicyclopentyltoluenes bp $150-154^{\circ} \mathrm{C}(2$ $\mathrm{mmHg}), n_{\mathrm{D}}^{20} 1.5393\left(\mathrm{bp} 150-152^{\circ} \mathrm{C}(2 \mathrm{mmHg})\right.$, $\left.n_{\mathrm{D}}^{20} 1.5391\right),{ }^{6} \mathrm{~m} / \mathrm{e} 228\left(\mathrm{M}^{+}\right)$(Found: C, 89.24\%; $\mathrm{H}, 10.76 \%$. Calcd: C, $89.47 \%$; H, $10.53 \%$ ).

Chromatography of the distillation residue on the silica-gel with hexane- $\mathrm{CCl}_{4}(1: 1)$ afforded an oil, i.e., mixed tricyclopentyltoluenes, $m / e 296\left(\mathrm{M}^{+}\right)$ (Found: C, $89.52 \%$; H, 10.48\%. Calcd: C, $89.19 \%$; $\mathrm{H}, 10.81 \%$ ).

\section{Measurement}

The copolymer composition was evaluated by elemental analysis. The intrinsic viscosity of the copolymers was determined in dimethylformamide at $30 \pm 0.01^{\circ} \mathrm{C}$. The $60 \mathrm{MHz}{ }^{1} \mathrm{H}$ NMR spectra of the copolymers were measured by a JNM-PMX60 spectrometer in $\mathrm{CDCl}_{3}$. The mass spectra were taken with a Hitachi RMU-7M mass spectrometer at $20 \mathrm{eV}$. The gel-permeation chromatographic measurement (GPC) was performed on a Toyosoda HLC-801A high speed liquid chromatograph, using a polystyrene-gel column $(4 \mathrm{ft}+$ precolumn): flow rate of THF $1.2 \mathrm{ml} \mathrm{min}^{-1}$, press. $35 \mathrm{~kg} \mathrm{~cm}^{-2}$. The gas chromatographic analyses (GCG) were made with a Yanagimoto GCG-550T gas chromatograph using a $1.5 \mathrm{~m} \times 5 \mathrm{~mm}$ column packed with Apiezon grease $\mathrm{L}$ on $10 \%$ chromosorb $\mathrm{W}-\mathrm{AW}$, at $185^{\circ} \mathrm{C}$, with $\mathrm{H}_{2}$ carrier gas at $3 \mathrm{~kg} \mathrm{~cm}^{-2}$.

\section{RESULTS AND DISCUSSION}

\section{Copolymerization of $C P$ with $A N$}

Table I shows that CP copolymerizes with AN complexed with a stoichiometric amount of EtAlCl${ }_{2}$. However, $\mathrm{Et}_{2} \mathrm{AlCl}$ and $\mathrm{Et}_{3} \mathrm{Al}$ were virtually inactive. This order of activity agreed with the order of the acid strength of aluminum compounds. The copolymer composition was consistently $1: 1$, independent of the feed monomer ratio. These 1:1 copolymers are considered to be the alternating copolymers. The yield and the molecular weight of copolymers were not so high even after a long period of polymerization. This is in contrast to the fact that CP polymerizes easily by a conventional Ziegler or cationic catalyst ${ }^{7}$ and that the free radical copolymerization of $\mathrm{CP}$ with $\mathrm{AN}$ produces $\mathrm{AN}$-rich random copolymers. ${ }^{8}$

In the copolymerization of AN with butadiene, an alternating copolymer was obtained using a 
Table I. Alternating copolymerization of $\mathrm{CP}$ with $\mathrm{AN}$ by ethylaluminum compounds at $0^{\circ} \mathrm{C}^{\mathrm{a}}$

\begin{tabular}{|c|c|c|c|c|c|c|}
\hline $\mathrm{AN}$ & $\mathrm{CP}$ & $\mathrm{AN} / \mathrm{AN}+\mathrm{CP}$ & Al-comp. & $\begin{array}{c}\text { Polymerization } \\
\text { time }\end{array}$ & $\begin{array}{c}\text { Polymer } \\
\text { yield }\end{array}$ & $\begin{array}{l}\text { AN content } \\
\text { in polymer }\end{array}$ \\
\hline $\mathrm{mmol}$ & $\mathrm{mmol}$ & $\mathrm{mol}^{\circ} \%$ & $\mathrm{mmol}$ & $\mathrm{h}$ & $\%$ & $\mathrm{~mol}^{\circ} \%$ \\
\hline 20 & 20 & 50 & $\mathrm{Et}_{3} \mathrm{Al} \quad 20$ & 20 & 0 & \\
\hline 20 & 20 & 50 & $\mathrm{Et}_{2} \mathrm{AlCl} 20$ & 20 & Trace & - \\
\hline 10 & 30 & 25 & $\mathrm{EtAlCl}_{2} \quad 10$ & 6 & 13.5 & 51.8 \\
\hline 20 & 20 & 50 & $\mathrm{EtAlCl}_{2} 20$ & 6 & 10.9 & $50.3^{b}$ \\
\hline 30 & 10 & 75 & $\mathrm{EtAlCl}_{2} 30$ & 6 & 5.8 & 52.7 \\
\hline
\end{tabular}

a Polymerization condition: toluene, $5 \mathrm{ml}$.

${ }^{\mathrm{b}}[\eta]_{\mathrm{DMF}}^{30^{\circ} \mathrm{C}}=0.13 \mathrm{dl} \mathrm{g}^{-1} ; T_{\mathrm{m}}=101-110^{\circ} \mathrm{C}$.

small amount of $\mathrm{EtAlCl}_{2}-\mathrm{VOCl}_{3},{ }^{9}$ and $\mathrm{VOCl}_{3}$ effectuated the regeneration of the organoaluminum halide. ${ }^{10}$ In the copolymerization of AN with vinyl chloride, $\mathrm{VOCl}_{3}$ was also an effective promotor. ${ }^{11}$ The various transition metal compounds used here are listed in Table II. In the presence of an equimolar amount of $\mathrm{EtAlCl}_{2}$ with respect to $\mathrm{AN}$, the alternating copolymerization proceeds more effectively with the addition of a small amount of the transition metal compound than without it.

Transition metal compounds such as $\mathrm{Cr}(\mathrm{acac})_{3}$, $\mathrm{CrCl}_{3}, \mathrm{Ti}(n-\mathrm{BuO})_{4}, \mathrm{VOCl}_{3}$, and $\mathrm{VO}(\mathrm{acac})_{2}$ accelerate the polymerization effectively, but none of them have any influence on the copolymer composition. In general, the yield increased with the amount of the transition metal compound except for the case of $\mathrm{Cr}(\mathrm{acac})_{3}$, although $\mathrm{Cr}(\mathrm{acac})_{3}$ was the most effective promotor. On the other hand, metal halides such as $\mathrm{CaCl}_{2}, \mathrm{BeCl}_{2}, \mathrm{MnCl}_{2}, \mathrm{NiCl}_{2}$, $\mathrm{CoCl}_{2}, \mathrm{CuCl}_{2}, \mathrm{ZnCl}_{2}$, and $\mathrm{FeCl}_{3}$ failed to accelerate the polymerization.

The above results indicate that the alternating copolymerization of olefinic donor-acceptor monomers is also possible in the presence of an aluminum compound with a transition metal compound in a manner similar to the alternating copolymerization of 1,3-diene with acrylic monomers. ${ }^{9}$ However, in the case of olefinic donor-acceptor monomers, the amount of the aluminum compound could not be reduced even in the presence of a promotor. The reason for this may be the lower polymerizability of the intermediate ternary complex among olefinic donor-acceptor monomers and the aluminum compound compared to that of the diolefinic donor-olefinic acceptor and aluminum
Table II. Effect of metal compounds on the copolymerization of $\mathrm{CP}$ with $\mathrm{AN}$ at $0^{\circ} \mathrm{C}$ for $3 \mathrm{~h}^{\mathrm{a}}$

\begin{tabular}{|c|c|c|c|c|}
\hline \multirow{2}{*}{$\begin{array}{l}\text { Metal } \\
\text { comp. }\end{array}$} & \multirow{2}{*}{$\begin{array}{c}\begin{array}{c}\text { Metal } \\
\text { comp./Al }\end{array} \\
\mathrm{mol}^{\circ} \%\end{array}$} & \multirow{2}{*}{$\frac{\begin{array}{c}\text { Polymer } \\
\text { yield }\end{array}}{\%}$} & \multirow{2}{*}{$\begin{array}{l}\text { AN content } \\
\text { in polymer } \\
\mathrm{mol} \%\end{array}$} & \multirow{2}{*}{$\frac{[\eta]_{\mathrm{DMF}}^{30^{\circ} \mathrm{C}}}{\mathrm{dl} \mathrm{g}^{-1}}$} \\
\hline & & & & \\
\hline \multirow[t]{2}{*}{$\mathrm{BCl}_{3}$} & 10 & $19.0^{\mathrm{b}}$ & 50.4 & 0.13 \\
\hline & 50 & $14.4^{\mathrm{b}}$ & - & 0.13 \\
\hline \multirow{2}{*}{$\mathrm{MgCl}_{2}$} & 1 & 21.1 & 52.6 & 0.13 \\
\hline & 10 & 22.2 & - & - \\
\hline $\mathrm{HgCl}_{2}$ & 10 & $33.9^{\mathrm{b}}$ & 51.8 & 0.13 \\
\hline $\mathrm{PbCl}_{2}$ & 10 & 37.4 & - & 0.13 \\
\hline \multirow[t]{3}{*}{$\mathrm{CrCl}_{3}$} & 0.1 & 17.5 & 50.1 & 0.12 \\
\hline & 1 & 41.1 & 50.1 & - \\
\hline & 10 & 57.8 & 50.2 & 0.13 \\
\hline \multirow[t]{3}{*}{$\mathrm{Ca}(\mathrm{acac})_{3}$} & 0.1 & 85.0 & 50.3 & 0.13 \\
\hline & 1 & 74.6 & 51.2 & 0.12 \\
\hline & 10 & 1.7 & 50.3 & - \\
\hline \multirow[t]{3}{*}{$\mathrm{Ti}(n-\mathrm{BuO})_{4}$} & $4 \quad 0.1$ & 13.3 & - & - \\
\hline & 1 & 13.5 & 52.3 & - \\
\hline & 10 & 84.5 & 51.5 & 0.13 \\
\hline \multirow[t]{3}{*}{$\mathrm{VO}(\mathrm{acac})_{2}$} & 0.1 & $15.0^{\mathrm{c}}$ & 50.8 & - \\
\hline & 1 & 23.2 & 52.2 & 0.13 \\
\hline & 10 & 46.8 & 50.6 & 0.13 \\
\hline \multirow[t]{3}{*}{$\mathrm{VOCl}_{3}$} & 0.1 & 13.6 & - & 0.10 \\
\hline & 1 & 24.0 & 51.2 & 0.13 \\
\hline & 10 & 41.0 & 50.5 & - \\
\hline
\end{tabular}

a Polymerization conditions: AN, $20 \mathrm{mmol}$; CP, 20 mmol; $\mathrm{EtAlCl}_{2} / \mathrm{AN}=1.0$ in molar ratio; toluene, $5 \mathrm{ml}$.

b $20 \mathrm{~h}$.

c Used for NMR measurement.

compound.

The copolymers of $\mathrm{CP}$ and $\mathrm{AN}$ were white solids of low molecular weight with intrinsic viscosity 
ranging from 0.12 to $0.14 \mathrm{dlg}^{-1}$. The copolymers were completely soluble in acetone, chloroform, acetonitrile and $\mathrm{N}, \mathrm{N}$-dimethylformamide but insoluble in hexane and benzene. The copolymers melted without decomposition between 110 and $135^{\circ} \mathrm{C}$.

\section{Copolymerization of $\mathrm{CH}$ with $\mathrm{AN}$}

$\mathrm{CH}$ is also copolymerizable with $\mathrm{AN}$, and usually AN-rich copolymers are obtained as shown in Table III. Polymerization was fairly slow in the presence of $\mathrm{EtAlCl}_{2}$ even in the presence of tránsition metal compounds. The low rate of copolymerization may be due to the steric hindrance of the cyclohexene

Table III. Copolymerization of $\mathrm{CH}$ with $\mathrm{AN}$ at $0^{\circ} \mathrm{C}$ for $4 \mathrm{~h}^{\mathrm{a}}$

\begin{tabular}{|c|c|c|c|}
\hline \multirow{2}{*}{$\begin{array}{l}\text { Transition } \\
\text { metal comp. }\end{array}$} & \multirow{2}{*}{$\begin{array}{c}\begin{array}{c}\text { Transition metal } \\
\text { comp./Al }\end{array} \\
\frac{\mathrm{mol} \%}{\mathrm{o}}\end{array}$} & \multirow{2}{*}{$\begin{array}{c}\begin{array}{c}\text { Polymer } \\
\text { yield }\end{array} \\
\%\end{array}$} & \multirow{2}{*}{$\begin{array}{c}\begin{array}{c}\text { AN-content } \\
\text { in polymer }\end{array} \\
\mathrm{mol} \%\end{array}$} \\
\hline & & & \\
\hline None & & 2.1 & 88.6 \\
\hline \multirow[t]{2}{*}{$\mathrm{Cr}(\mathrm{acac})_{3}$} & 10 & Trace & - \\
\hline & 1 & Trace & - \\
\hline $\mathrm{CrCl}_{3}$ & 10 & 7.6 & 73.6 \\
\hline $\mathrm{Ti}(\mathrm{OEt})_{3} \mathrm{Cl}$ & 10 & 12.1 & 86.2 \\
\hline $\mathrm{VOCl}_{3}$ & 10 & 18.3 & 88.7 \\
\hline $\mathrm{VO}(\mathrm{acac})_{2}$ & 10 & 1.6 & 84.3 \\
\hline
\end{tabular}

a Polymerization conditions: AN, $20 \mathrm{mmol}$; $\mathrm{CH}, 20$ mmol; $\mathrm{EtAlCl}_{2}, 20 \mathrm{mmol}$; toluene, $5 \mathrm{ml}$. ring $^{1,8}$ and the side reactions mentioned below. Table IV shows the copolymer composition to be remarkably influenced by the solvent used. The AN content in the copolymers obtained in toluene and tetrachloroethane was higher than $50 \%$, regardless of the monomer composition. On the other hand, the copolymers prepared in heptane had nearly $50 \%$ of the AN units. However, the yield and molecular weight were also low.

The intrinsic viscosity of the copolymers was about $0.13 \mathrm{dlg}^{-1}$. The AN-rich copolymers were found to decompose at $173-190^{\circ} \mathrm{C}$. On the other hand, the $1: 1$ copolymer melted without decomposition in the temperature range of $148-156^{\circ} \mathrm{C}$ and was soluble in acetone, chloroform and acetonitrile.

\section{Friedel-Crafts Reaction}

In the reaction of $\mathrm{CH}$ with $\mathrm{AN}$ or $\mathrm{CP}$ with $\mathrm{AN}$ in toluene the Friedel-Crafts reaction was found to primarily occur as shown in Table $\mathrm{V}$. The yield of the reaction products of $\mathrm{CH}$-toluene was higher than that of $\mathrm{CP}$-toluene. The catalyst composed of Et $\mathrm{AlCl}_{2}-\mathrm{VOCl}_{3}$ was the most active in the FriedelCrafts reaction. Tri-substituted toluenes were the main products in the reaction of $\mathrm{CH}$ or $\mathrm{CP}$ and toluene even in the presence of $\mathrm{AN}$, indicating the preferential reaction of cycloolefin toward a proton and the high reactivity of a cycloalkyl cation with toluene. A trace amount of water remaining in the reaction system may act as a proton source.

Table IV. Copolymerization of $\mathrm{CH}$ with $\mathrm{AN}$ by $\mathrm{EtAlCl}_{2}$ in various solvents at $0^{\circ} \mathrm{C}$ for $4 \mathrm{~h}$

\begin{tabular}{|c|c|c|c|c|c|c|c|}
\hline \multirow{2}{*}{$\frac{\mathrm{AN}}{\mathrm{mmol}}$} & \multirow{2}{*}{$\frac{\mathrm{CH}}{\mathrm{mmol}}$} & \multicolumn{2}{|l|}{ Solvent } & \multirow{2}{*}{$\frac{\mathrm{EtAlCl}_{2}}{\mathrm{mmol}}$} & \multirow{2}{*}{$\begin{array}{l}\text { Transition } \\
\text { metal comp. }\end{array}$} & \multirow{2}{*}{$\frac{\begin{array}{c}\text { Polymer } \\
\text { yield }\end{array}}{\%}$} & \multirow{2}{*}{$\begin{array}{l}\text { AN content } \\
\text { in polymer } \\
\mathrm{mol} \%\end{array}$} \\
\hline & & $\mathrm{ml}$ & & & & & \\
\hline 10 & 30 & Tol & 5 & 10 & None & 0.5 & 91.1 \\
\hline 20 & 20 & & 5 & 20 & & 1.2 & 88.7 \\
\hline 30 & 10 & & 5 & 30 & & 1.6 & 79.6 \\
\hline 10 & 30 & TCE & 5 & 10 & $\mathrm{VOCl}_{3}$ & 4.4 & 61.7 \\
\hline 20 & 20 & & 5 & 20 & & 4.9 & 56.6 \\
\hline 30 & 10 & & 5 & 30 & & 6.3 & 64.0 \\
\hline 10 & 30 & Heptane & 5 & 10 & $\mathrm{Cr}(\mathrm{acac})_{3}$ & $0.2^{\mathrm{b}}$ & 52.5 \\
\hline 20 & 20 & & 5 & 20 & & $1.1^{\mathrm{b}}$ & $51.5^{\mathrm{c}}$ \\
\hline 30 & 10 & & 5 & 30 & & $0.5^{\mathrm{b}}$ & 53.0 \\
\hline
\end{tabular}

a Transition metal comp./ $\mathrm{EtAlCl}_{2}=0.1$ in molar ratio.

b $[\eta]_{\mathrm{DMF}}^{30^{\circ} \mathrm{C}}=0.13 \mathrm{dl} \mathrm{g}^{-1}$.

c Used for NMR measurement. 
Table V. Friedel-Crafts reaction of cycloolefin with toluene at $0^{\circ} \mathrm{C}$ for $3 \mathrm{~h}$

\begin{tabular}{|c|c|c|c|c|c|c|c|c|c|c|c|}
\hline \multirow{3}{*}{$\frac{\mathrm{AN}}{\mathrm{mmol}}$} & \multirow{2}{*}{\multicolumn{2}{|c|}{ Cycloolefin }} & \multirow{3}{*}{$\frac{\text { Toluene }}{\mathrm{ml}}$} & \multirow{3}{*}{$\frac{\mathrm{EtAlCl}_{2}}{\mathrm{mmol}}$} & \multirow{2}{*}{\multicolumn{2}{|c|}{$\begin{array}{l}\text { Transition } \\
\text { metal comp. }\end{array}$}} & \multirow{3}{*}{$\begin{array}{c}\begin{array}{c}\text { Polymer } \\
\text { yield }\end{array} \\
\%\end{array}$} & \multicolumn{4}{|c|}{ Friedel-Crafts product } \\
\hline & & & & & & & & \multirow{2}{*}{$\frac{\text { Yield }^{\mathrm{a}}}{\mathrm{mol}^{\circ} \%}$} & \multirow[t]{2}{*}{$A^{b}$} & $\mathbf{B}^{\mathbf{b}}$ & \multirow[t]{2}{*}{$\mathrm{C}^{\mathrm{b}}$} \\
\hline & \multicolumn{2}{|c|}{ mmol } & & & \multicolumn{2}{|c|}{ mmol } & & & & $\mathrm{mol} \%$ & \\
\hline 20 & $\mathrm{CH}$ & 20 & 5 & 20 & None & & 2.1 & 20.0 & 40.9 & 20.8 & 38.3 \\
\hline 20 & $\mathrm{CH}$ & 20 & 5 & 20 & $\mathrm{VOCl}_{3}$ & 0.5 & 8.3 & 62.0 & 31.4 & 16.0 & 52.6 \\
\hline 20 & $\mathrm{CH}$ & 20 & 5 & 20 & $\mathrm{Ti}(n-\mathrm{BuO})_{4}$ & 0.5 & 3.5 & 35.0 & 38.5 & 8.4 & 53.1 \\
\hline 0 & $\mathrm{CH}$ & 20 & 5 & 20 & $\mathrm{CrCl}_{3}$ & 1.0 & 4.2 & 12.3 & 44.9 & 24.8 & 30.3 \\
\hline 0 & $\mathrm{CH}$ & 20 & 5 & 20 & $\mathrm{VOCl}_{3}$ & 0.05 & - & 43.0 & 28.9 & 13.2 & 57.9 \\
\hline 20 & $\mathrm{CP}$ & 20 & 5 & 20 & None & & 10.9 & 21.0 & 8.5 & 17.9 & 73.6 \\
\hline 0 & $\mathrm{CP}$ & 20 & 5 & 20 & $\mathrm{VOCl}_{3}$ & 0.05 & - & 33.0 & 13.2 & 23.0 & 63.8 \\
\hline
\end{tabular}

a The yield was calculated based on $\mathrm{CH}$ or $\mathrm{CP}$ in the feed.

b Product distribution was determined by GPC analysis: A, cyclohexyltoluene or cyclopentyltoluene; B, dicyclohexyltoluene or dicyclopentyltoluene; $\mathrm{C}$, tricyclohexyltoluene or tricyclopentyltoluene.

Table VI. Copolymerization of CPD with $\mathrm{AN}$ at $15^{\circ} \mathrm{C}$ for $3 \mathrm{~h}^{\mathrm{a}}$

\begin{tabular}{|c|c|c|c|c|c|}
\hline AN & CPD & EtAlCl${ }_{2}$ & $\begin{array}{l}\text { Polymer } \\
\text { yield }\end{array}$ & $\begin{array}{l}\text { AN content } \\
\text { in polymer }\end{array}$ & $\begin{array}{l}\text { Yield of Diels-Alder } \\
\text { product }^{\mathrm{b}}\end{array}$ \\
\hline $\mathrm{mmol}$ & $\mathrm{mmol}$ & $\mathrm{mmol}$ & $\%$ & $\mathrm{~mol}^{\circ} \%$ & $\mathrm{~mol}^{\circ} \%$ \\
\hline 10 & 30 & 2.5 & 7.0 & 29.0 & 47.7 \\
\hline 20 & 20 & 5.0 & 5.9 & 60.0 & 29.0 \\
\hline 30 & 10 & 7.5 & 4.3 & 77.0 & 23.2 \\
\hline 10 & 30 & 5.0 & 7.1 & 24.2 & 31.5 \\
\hline 20 & 20 & 10.0 & 7.0 & 46.5 & 27.0 \\
\hline 30 & 10 & 15.0 & 4.5 & 53.3 & 36.2 \\
\hline 10 & 30 & 7.5 & 6.6 & 33.1 & 42.6 \\
\hline 20 & 20 & 15.0 & 7.1 & $40.2^{c}$ & 26.7 \\
\hline 30 & 10 & 22.5 & 5.5 & $49.2^{\mathrm{d}}$ & 32.0 \\
\hline 10 & 30 & 9.0 & 6.3 & 8.0 & 38.7 \\
\hline 20 & 20 & 18.0 & 18.9 & 21.0 & 18.4 \\
\hline 30 & 10 & 27.0 & 3.8 & 25.0 & 29.8 \\
\hline
\end{tabular}

a Polymerization condition: toluene $6 \mathrm{ml}$.

b The retention time of 2-cyanobicyclo[1.2.2]hept-5-ene, bp $95-97^{\circ} \mathrm{C}(20 \mathrm{mmHg})\left[\mathrm{bp} 84-89^{\circ} \mathrm{C}(13 \mathrm{mmHg})\right],{ }^{13} \mathrm{was}$ the same as that of the authentic sample by GCG. The yield was calculated based on CPD in the feed.

c Used for NMR measurement.

${ }^{\mathrm{d}}[\eta]_{\mathrm{DMF}}^{30^{\circ} \mathrm{C}}=0.65-0.81 \mathrm{dl} \mathrm{g}^{-1} ; T_{\mathrm{m}}=155-175^{\circ} \mathrm{C}$ (brown colored).

\section{Copolymerization of CPD with AN}

The copolymerization of CPD with $\mathrm{AN}$ was attempted in the presence of $\mathrm{EtAlCl}_{2}$ as a complexing agent, and the results are summarized in Table VI. The copolymer composition was considerably affected by the amount of $\mathrm{EtAlCl}_{2}$ and the polymerization temperature, as in the copolymerization of benzofuran-AN. ${ }^{12}$ With increasing or decreasing amount of $\mathrm{EtAlCl}_{2}$, the $\mathrm{AN}$-content deviated from
$50 \%$, even at the optimum temperature $\left(15^{\circ} \mathrm{C}\right)$, and the use of an optimum amount of $\mathrm{EtAlCl}_{2}$ $(\mathrm{Al} / \mathrm{AN}=0.75$ molar ratio) diminished the deviation of the $\mathrm{AN}$ content from $50 \%$. The addition of $\mathrm{VOCl}_{3}$ as a promotor to these systems was not effective. These facts may be due to the high reactivity of CPD toward cationic species. The $1: 1$ copolymer of CPD with AN was a white solid, high in molecular weight and soluble in $N, N$-dimethyl- 


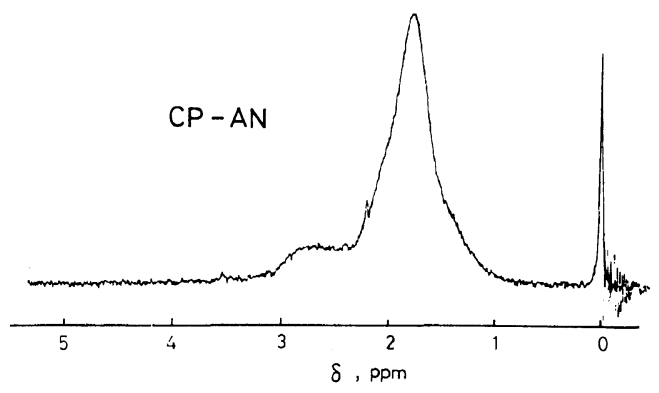

$\mathrm{CH}-\mathrm{AN}$
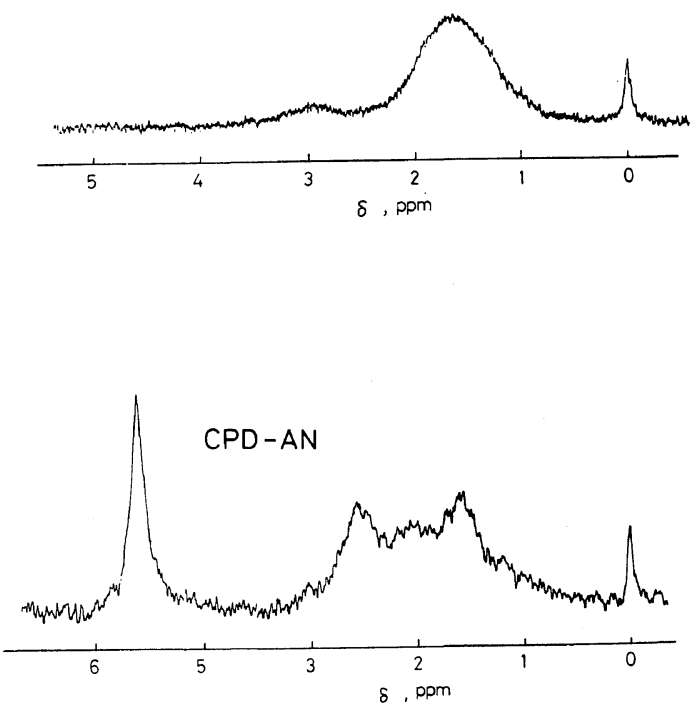

Figure 1. NMR spectra of copolymers at $36^{\circ} \mathrm{C}$. AN content: $\mathrm{CP}-\mathrm{AN}, 50.8 \%$; $\mathrm{CH}-\mathrm{AN}, 51.5 \%$; CPD-AN, $42.0 \%$.

formamide, acetone and chloroform. The intrinsic viscosity of the copolymers ranged from 0.65 to $0.81 \mathrm{dlg}^{-1}$ in DMF. However, the copolymers were easily oxidized by air and found to give polymers containing carbonyl groups from the absorption at $1655 \mathrm{~cm}^{-1}$ in the infrared spectra.

In the present system, the main reaction was a Diels-Alder reaction even at a low temperature $\left(-30^{\circ} \mathrm{C}\right)^{13}$ because of the extremely high reactivity of CPD with AN complexed with a Lewis acid.

\section{${ }^{1}$ H NMR Spectra of Copolymers}

$60 \mathrm{MHz}{ }^{1} \mathrm{H}$ NMR spectra of copolymers of AN with $\mathrm{CP}, \mathrm{CH}$, or $\mathrm{CPD}$ were measured in $\mathrm{CDCl}_{3}$ and are illustrated in Figure 1. The AN-CP and AN$\mathrm{CH}$ copolymers gave simple but broad spectrum patterns having two peaks. One peak at $\delta 2.8-3.0$ was assigned to the proton attached to the $\alpha$-carbon of the acrylonitrile unit and the other at $\delta 0.9-2.5$, to the methylene protons, giving little information on the sequence distribution.

Two modes of the reaction are possible in the addition of $\mathrm{AN}$ to the 1,3-cyclopentadiene, i.e., the 1,2- and 1,4-addition. The product in the 1,2addition should have one allylic methine $\left(\mathrm{H}_{\mathrm{b}}\right)$, one allylic methylene $\left(2 \mathrm{H}_{\mathrm{c}}\right)$, and one ordinary methine $\left(\mathrm{H}_{\mathrm{d}}\right)$ on the cyclic unit and that in the 1,4-addition, two allylic methines $\left(2 \mathrm{H}_{\mathrm{b}}\right)$ and two methylene protons $\left(2 \mathrm{H}_{\mathrm{e}}\right)$. The ${ }^{1} \mathrm{H}$ NMR spectrum of the present copolymer of CPD and AN (AN content $=42 \%$ ) is very complicated. The peak at $\delta 5.6$ is assigned to the olefin proton $\left(\mathrm{H}_{\mathrm{a}}\right)$ and the signal at $\delta 1.5$ to the<smiles>CCC(C)C1C=CC(C)C1(C)C</smiles>

1,2-addition<smiles>CCCC1C=CC(C)C1(C)C</smiles>

1,4-addition methylene protons $\left(\mathrm{H}_{\mathrm{e}}\right)$ and $\left(\mathrm{H}_{\mathrm{g}}\right)$. The proton $\left(\mathrm{H}_{\mathrm{f}}\right)$ neighboring the nitrile group is considered to appear in the lower field than $\mathrm{H}_{b}, \mathrm{H}_{\mathrm{c}}$, or $\mathrm{H}_{\mathrm{d}}$, and is perhaps involved in the signal at $\delta 2.5-3.0$. Although the allylic methylene $\left(\mathrm{H}_{\mathrm{c}}\right)$ and the methine $\left(\mathrm{H}_{\mathrm{d}}\right)$ signal of CPD-CPD dyad in the 1,2-addition polymer are known to appear at about $\delta 2.2,{ }^{14}$ they were indistinguishable from the AN-CPD dyad.

The area ratio of $\mathrm{S}_{\mathrm{A}}: \mathrm{S}_{\mathrm{B}}: \mathrm{S}_{\mathrm{C}}: \mathrm{S}_{\mathrm{D}}$ in the NMR chart, corresponding to the peaks at $\delta 0.7-1.8$, $\delta 1.8-2.3, \delta 2.3-3.2$, and $\delta 5.2-6.0$, respectively, is $2: 2.6: 1: 2.4$. In the alternating copolymer produced by the 1,4-addition or by the 1,2-addition, the area ratio should be $2\left(\mathrm{~S}_{\mathrm{A}}\right): 3\left(\mathrm{~S}_{\mathrm{B}}\right): 4\left(\mathrm{~S}_{\mathrm{D}}\right)$ or $2\left(\mathrm{~S}_{\mathrm{A}}\right)$ : $3\left(\mathrm{~S}_{\mathrm{B}}\right): 2\left(\mathrm{~S}_{\mathrm{C}}\right): 2\left(\mathrm{~S}_{\mathrm{D}}\right)$, respectively.

In conclusion, it is suggested that both the 1,4addition and 1,2-addition occur simultaneously in this system. This is at variance with the copolymerization of CPD-sulfur dioxide ${ }^{3}$ and 1,3-cyclooctadiene-acrylic monomer. ${ }^{15} \mathrm{~A}$ complexing agent may induce cationic species for the cationic polymerization of CPD resulting in an irregular opening of CPD unit together with the alternating copolymerization and the Diels-Alder reaction. 


\section{REFERENCES}

1. G. Natta, G. Dall'asta, G. Mazzanti, I. Pasquon, A. Valvassori, and A. Zambelli, Makromol. Chem., 54, 951 (1962).

2. Sumitomo Chem. Ind. Co., Br. Patent, 1123724 (1968).

3. T. Yamaguchi and T. Ono, Chem. Ind. (London), 769 (1968).

4. W. J. Hickinbottom and N. W. Roger, J. Chem. Soc., 4124 (1957).

5. N. G. Sidorova and I. I. Kartseva, Zh. Obshch. Khim., 32, 2785 (1962).

6. E. S. Pokrovskaya, Trud. Inst. Nefti. Akad. Nauk. S.S.S.R., 1, 264 (1950).

7. J. Boor, E. A. Youngan, and M. Dimbat, Makromol. Chem., 90, 26 (1966).
8. K. Yasufuku, S. Nozakura, and S. Murahashi, Bull. Chem. Soc. Jpn., 40, 2146 (1967).

9. J. Furukawa and Y. Iseda, J. Polym. Sci., B, 7, 47 (1969); J. Furukawa, Y. Iseda, K. Haga, and N. Kataoka, J. Polym. Sci., A-1, 8, 1147 (1970).

10. J. Furukawa, E. Kobayashi, and Y. Iseda, Polym. J., 1, 155 (1970).

11. J. Furukawa, E. Kobayashi, and J. Yamauchi, Polym. J., 2, 407 (1971).

12. J. Furukawa, E. Kobayashi, and S. Nagata, $J$. Polym. Sci., Polym. Chem. Ed., 16, 2945 (1978).

13. K. Alder, H. Krieger, and H. Weiss, Chem. Ber., 88, 144 (1955).

14. C. Aso, O. Ohara, and T. Kunitake, Kobunshi Kagaku, 27, 97 (1970).

15. J. Furukawa, E. Kobayashi, and S. Nagata, Polym. J., 9, 633 (1977). 